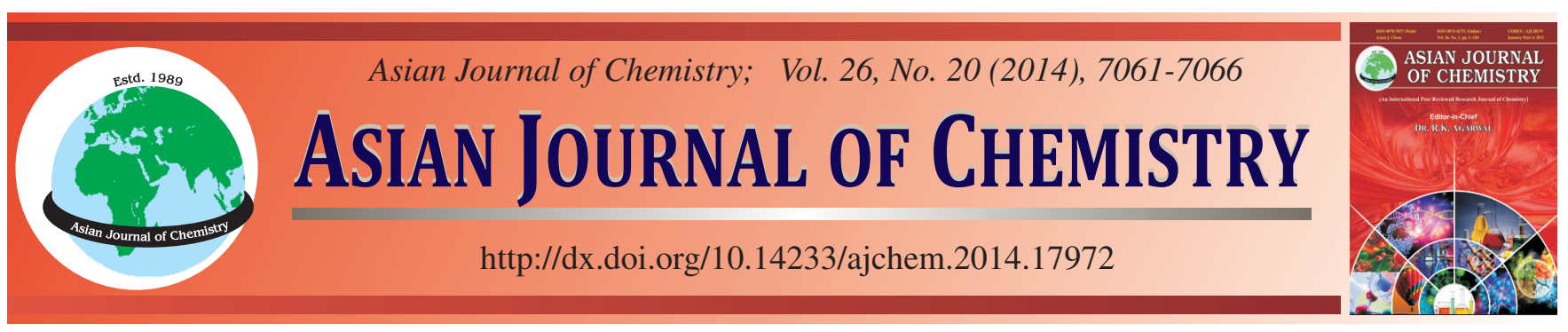

\title{
Study of Cross-Linked Poly( $N$-vinyl-2-pyrrolidone) Gel and Its Uses in the Controlled Release of Antiinflammatory Drug Diclofenac Sodium
}

\author{
Farhat Ali $\mathrm{Khan}^{1}$, Sudhair Abbas ${ }^{2}$, Bashir Ahmad ${ }^{3}$, Naser M. Abdei-Salam ${ }^{4}$ and Riaz Ullah ${ }^{5, *}$
}

\begin{abstract}
${ }^{1}$ Department of Pharmacy, Sarhad University of Science and Information Technology, Peshawar, Pakistan
${ }^{2}$ Department of Pharmacy, Abasyn University, Peshawar, Pakistan

${ }^{3}$ Centre of Biotechnology and Microbiology, University of Peshawar, Peshwar, Pakistan

${ }^{4}$ Riyadh Community College, King Saud University, Riyadh 11437, Saudi Arabia

${ }^{5}$ Department of Chemistry, Government College, Ara Khel FR Kohat,Pakistan

*Corresponding author: E-mail: afridiriaz@yahoo.com
\end{abstract}

Received: 9 May 2014;

Accepted: 19 August 2014;

Published online: 25 September 2014;

AJC-16067

\begin{abstract}
The objective of present study was to synthesize poly( $N$-vinyl-2-pyrrolidone) gel with different compositions, characterized and used as carrier for different of drugs. Three formulations with different ratios (drugs-hydrogel ratio 1:1, 1:2 and 1:3) were prepared. The released of drug from hydrogels followed both diffusion and erosion. The hydrogel was compressed with diclofenac sodium at different ratios (drugs-hydrogel ratio 1:1, 1:2 and 1:3). After being compressed, matrix tablets were put into dissolution medium in order to test the release mechanism of diclofenac sodium from compressed tablets and its release time. The sustainability of diclofenac sodium (1:1) was $5.5 \mathrm{~h}$ and the drug release from compressed tablets was $92 \%$. The sustainability of diclofenac sodium (1:2) was $8 \mathrm{~h}$ and the drug release from matrix tablets was $85 \%$. The results obtained at $1: 3$ showed $77 \%$ of diclofenac sodium was released after $13 \mathrm{~h}$. The present study revealed that drugs and hydrogel at 1:3 was proficient for supporting the diclofenac sodium for longer period of time as compared with other drug/polymer ratios $(1: 1$ and $1: 2)$.
\end{abstract}

Keywords: Diclofenac sodium, Sustained release, Poly( $N$-vinyl-2-pyrrolidone) Hydrogels, Dissolution media.

\section{INTRODUCTION}

While reducing side effects, pharmaceutical invention and research concentrate more on delivery system which arises required therapeutic objectives ${ }^{1}$. Current developments show that controlled or belated release oral formulations are achieved appropriately by multi-particulate drug delivery systems with low risk of dose discarding and flexibility of amalgamation in order to get different release prototypes as well as reproducible and short gastric residence time ${ }^{2}$. Different factors including the carrier, used to form the multi-particles, are accountable for release of drug from multi-particles and the amount of drug contained in them. Consequently, expanding the boundary of future pharmaceutical development multi-particulate drug delivery systems impart enormous opportunities to design new controlled and belated release oral formulations ${ }^{3}$.

Hydrogels, composed of hydrophilic homopolymers or copolymers, are organic compounds with three dimensional structures which are physically or chemically cross linked ${ }^{4}$. They are widely used as sensors, separation membranes, absorbents and materials in medicine due to their consummate applications. They are also used enormously in pharmacy as drug delivery systems because they are biocompatible, biodegradable and non toxic ${ }^{5,6}$. Hydrogels have played significant role in solving some ecological and biological problems in modern technologies. These physically or chemically cross-linked hydrogels show a swelling behaviour up to thousand times to their own weight in aqueous media ${ }^{7}$. The cross-linked property provides them network structure and physical integrity.

Numerous researches were carried out on the dynamic behaviour of polymeric hydrogels including increasingly new and more complex macromolecular systems. They can be designed with required swelling properties and mechanical modulus. They are strongly reliant on several chemical and structural factors such as degree of cross linking, density and type of fixed charges, hydrophilicity of polymer backbone, amount of ionic groups and ultimate presence of porosity. They are also dependent on the properties of the aqueous solution in contact with the network such as ionic strength, $\mathrm{pH}$ and presence of other solvents ${ }^{8}$. Inflammation is a complex reaction in tissues that consists mainly of responses of blood vessels and leukocytes. Inflammation may be acute or chronic, 
depending on the nature of the stimulus and the effectiveness of the initial reaction in eliminating the stimulus or the damaged tissues. Acute inflammation is rapid in onset (typically minutes) and is of short duration, lasting for hours or a few days. Its main characteristics are the exudation of fluid and plasma proteins (edema) and the emigration of leukocytes, predominantly neutrophils (also called polymorphonuclear leukocytes). Chronic inflammation may follow acute inflammation or be insidious in onset. It is of longer duration and is associated with the presence of lymphocytes and macrophages, the proliferation of blood vessels, fibrosis and tissue destruction ${ }^{9}$. Diclofenac is a phenylacetic acid derivative that is relatively nonselective as a COX inhibitor. A preparation combining diclofenac and misoprostol decreases upper gastrointestinal ulceration but may result in diarrhea. Another combination of diclofenac and omeprazole was also effective with respect to the prevention of recurrent bleeding, but renal adverse effects were common in high-risk patients. Diclofenac at a dosage of $150 \mathrm{mg} / \mathrm{d}$ appears to impair renal blood flow and glomerular filtration rate. Elevation of serum aminotransferases may occur more commonly with this drug than with other NSAIDs ${ }^{10}$.

\section{EXPERIMENTAL}

Ethylene dimethacylate (EDMA) (Fisher scientific), triethylene glycol divinyl ether (DEV-3) (Sigma), divinyl benzene (DVB) (Fisher scientific), ammonium per sulphate (APS) (Merck chemicals), diclofenac sodium (Sigma) and deionized water. Similarly, dextran, bovine serum albumin (BSA) and poly(vinyl pyrrolidonee) (PVP) (Sigma) sample grade, vinyl pyrrolidone (VP) (Sigma), N,N-methylene bis acrylamide (BIS) (Morgan chemicals), azo-iso-butyronitrile (AIBN) (Merck chemicals).

Evaluation of tablets: Assessment of matrix tablets for physical properties like weight variation, hardness, friability and in vitro dissolution study were carried out.

Uniformity of weight: In a batch every individual tablet was in uniform weight and weight variation of matrix tablets are in within acceptable limits. The weights of matrix tablets were ascertained within $\pm 1 \mathrm{mg}$. By using sartorius balance was used for measurements, control of matrix tablets weight was based on a sample of 20 tablets.

Dimensions: Digital vernier calipers were utilized for the measurement of the dimensions (thickness and diameter) to within $\pm 0.01 \mathrm{~mm}$.

Hardness: Tablets hardness testing apparatus (Monsanto Type) was used for the determination of the hardness of the tablets. Tablet hardness was about $5-6 \mathrm{~kg}$ is believed to be sufficient for its mechanical strength. Hardness of matrix tablets was measured in triplicate.

Friability: Roche friabilator was used for the determination of the friability of the tablets. Known weight of matrix tablets (W0) or a sample of 50 matrix tablets was dedusted in a drum for a time period (4000 revolutions) and again weighed precisely (W). Percent friability was computed from loss in weight in equation as given below. The loss of weight must be less than $1 \%$.

$$
2.9 \% \text { Friability }=\left(\mathrm{W}_{1}-\mathrm{W}_{2}\right) / \mathrm{W}_{1} \times 100
$$

Evaluation of granules: Most powders do not flow freely that produces problems like weight variation, thickness, hardness and friability of the tablets during production that affect the disintegration and dissolution which ultimately effect the bioavailability of drug for this reason to overcome this problem powders are converted into granules that are free-flowing and can be easily compressed into tablets. Therefore the granules were evaluated for the following physical properties.

Angle of repose: The fixed funnel method was utilized to measure angle of repose. The accurately pre-weighed granule was moved to a funnel having an orifice of $8 \mathrm{~mm}$, protected with its tip at a specified height "h", above a circular dish of radius "r". The powders/granules were acceptable for flow freely through the funnel onto the surface until the apex of the conical pile just touches the tip of the funnel. The granules/ powder cone diameter was calculated and angle of repose was measured according to the subsequent equation.

$$
\tan \theta=\mathrm{h} / \mathrm{r}
$$

where $\mathrm{h}$ and $\mathrm{r}$ are the height and radius of the powder cone, respectively.

Bulk density: Both loose bulk density (LBD) and tapped bulk density (TBD) were determined for the granules before compression $9.3 \mathrm{~g}$ of granules from each formulation, lightly shaken in order to break any agglomerates if formed, was poured into a $10 \mathrm{~mL}$ graduated cylinder. The initial volume was noted and then the cylinder was permitted to fall on a hard surface from a height of $2.5 \mathrm{~cm}$ at 2 second intervals of time. The tapping was carried out until no further change was observed in its volume ${ }^{10}$. The LBD and TBD were determined by using the following formulas.

LBD $=$ weight of the powder/volume of the packing

TBD = weight of the powder/tapped volume of the package

Compressibility index: Carr's compressibility index was used for the measurement of compressibility index of the granules by the following equation ${ }^{11}$.

$$
\text { Carr's index }(\%)=(\text { TBA-LBD }) \times 100 / T B D
$$

Drug content of granules and tablets of diclofenac Sodium: An accurately weighed quantity of granules/tablets containing $100 \mathrm{mg}$ of diclofenac sodium were finely ground with the help of mortar and pestle and suspended in $100 \mathrm{~mL}$ methanol by mechanical stirrer (EZ Stir) for $10 \mathrm{~min}$ to extract the diclofenac sodium. The suspension was filtered through Wattman filter paper. The filtrate was diluted to a concentration of $20 \mu \mathrm{g} / \mathrm{mL}$ with methanol and the content of diclofenac sodium was determined spectrophotometrically at $267 \mathrm{~nm}$ in comparison with a standard diclofenac sodium solution having the same concentration of USP diclofenac sodium SR in the same medium using UV/visible spectrophotometer (Lambda 25, Perkin Elmer) ${ }^{12}$.

Preparation of matrix tablets: To fabricate the different formulation of tablets various drug-hydrogel ratios were used. Matrix tablets were then subjected to different physical (friability, weight variation and hardness thickness) and chemicals tests (assay and content uniformity) for their evaluation. The following method was used for compression of the hydrogel and drug into tablets. The triturating of dried hydrogels was carried out in a porcelain mortar and pestle followed by their passing through mesh No. 20. Diclofenac sodium were passed 
through the mesh No. 20. In order to keep the amounts of diclofenac sodium constant, the powder drug and hydrogels were then mixed with ratio of 1:1, 1:2 and 1:3. Compression of the mixture was done by using rotary tablet compression machine. The machine had $8 \mathrm{~mm}$ round punches for 1:1, 1:2 and $1: 3$ ratios mixtures respectively.

in vitro Release studies: Evaluation of the in vitro dissolution studies was done by the dissolution apparatus II used as mentioned in US Pharmacopeia. Studies of in vitro release of drug, from the prepared matrix tablets were performed for a period of $12 \mathrm{~h}$. A six station USP type II apparatus was used at $37 \pm 0.5^{\circ} \mathrm{C}$ and $50 \mathrm{rpm}$. Experiment was performed in triplicate for $12 \mathrm{~h}$ (initial $2 \mathrm{~h}$ within $0.1 \mathrm{~N} \mathrm{HCl}$. Rest $10 \mathrm{~h}$ were in phosphate buffer solution of $\mathrm{pH} 6.8$ under sinks condition. the samples were drawn after every $1 \mathrm{~h}$ from the dissolution medium which was then replaced with fresh medium for maintaining the constant volume. Following filtration and appropriate dilution, the sample solution was analyzed at absorption maxima of $268 \mathrm{~nm}$ for diclofenac sodium, using a UV-visible spectrophotometer. The concentration of drug present in the samples was determined with the help of appropriate standard curves constructed from reference standards in which the quantity of drug dissolved at specified periods of time was plotted as percent release versus time (hours) curve in y axis and $\mathrm{x}$ axis respectively.

Data analysis: The result obtained after the dissolution data obtained for hydrogel discs and matrix tablets were then analyzed and these results were then tested using different mathematical model. The inner regression was applied for the whole obtained to data in all model to evaluate the released of drugs mechanisms.

Release kinetics: The release kinetics of diclofenac sodium were studied from the matrix tablets, the release data were subjected to the Higuchi's equation, Hixson-Crowell, Zero order equation, First order equation and Qt/Q $\infty=k K P . \mathrm{tn}^{13}$. For the case of cylindrical geometries such as tablets, $n=0.45$ which corresponds to a Fickian diffusion release.

\section{RESULTS AND DISCUSSION}

Physical characteristics of tablets and granules/powder: Matrix tablets of diclofenac sodium were yellowish in colour. In all formulations, the tablets were round with same diameter and thickness i.e. 10 and $12 \mathrm{~mm}$, respectively. All the batches of tablets prepared with hydrogels were passed for the entire physical test like weight variation tests, thickness, hardness and friability. The tablets of different formulations were subjected to various evaluation tests were performed on the various formulation of tablets, such as friability, weight variation of matrix tablets, thickness, contents of drug, hardness, diameter and in vitro testing of dissolution ${ }^{14-17}$. All the prepared matrix tablets illustrated uniform thickness as well as weight variation test, the pharmacopoeial limit (USP) in a weight variation test of matrix tablets for the percentage deviation of more than $350 \mathrm{mg}$ is $\pm 5 \%$. For all the tablet formulations the average percentage deviation was established to be within the limit as stated above and hence, as per official requirements all the formulations of tablets passed the test for uniformity of weight. The data also showed that the flow characteristics as well as compressibility property of hydrogels and drug were fall in acceptable range ${ }^{18}$. Therefore, on the basis of above data all the different formulations showed that physical parameters were within control limit.

Evaluation of the granules/powders: Physical properties of granules such as angle of repose, LBD, TBD compressibility index and drug content were evaluated to study their effects on the characteristics of the tablets the results are shown in the Table-1.

The angle of repose of all the granules was determined. For all formulations, it was less than 300 which indicated good flow properties. The results of LBD and TBD were observed in the range of $0.45 \pm 0.04-0.48 \pm 0.03$ and $0.47 \pm 0.03-0.54 \pm$ 0.03 . These results showed that the formed granules were round and spherical. Another extrinsic property of the granules, the compressibility index, was also determined. It was from 15.26 \pm 0.05 to $16.61 \pm 0.05 \%$ for all these formulations that also confirmed the optimum flow properties. Granules having compressibility index values up to $21 \%$ or below this range showed good flow properties. Table-1 shows increase in polymer resulted in increase in the values of loose bulk density and taped bulk density. The possible reason could be that high concentrations of polymer increase the binding forces which increase the LBD and TBD. These increased binding forces may also increase the values of angle of repose and compressibility index. The results of the above tests provided the evidence that the granules of all the three formulations were in conformation with that of a good formulation ${ }^{19}$.

Evaluation of the matrix tablets: The tablets of the proposed formulations ( $\mathbf{2} \mathbf{a}, \mathbf{2} \mathbf{b}$ and $\mathbf{2 c}$ ), after being compressed into tablets, were tested for their physical considerations. The mean thickness $(n=20)$ of the table were found to be falling in the range of $5.16 \pm 0.03$ to $7.09 \pm 0.04 \mathrm{~mm}$. Also, the mean hardness $(n=20)$ of the matrix tablets was in order of $6.5 \pm 3.23$ to $9 \pm 2.82 \mathrm{Kg}$. The $\%$ friability was in the range of $0.25 \pm 0.02$ to $0.49 \pm 0.02 \%$ i.e. $<1 \%$. The results for weight variation of twenty tablets of each formula were less than $\pm 5 \%$. All the formulations were assayed for the chemical tests i.e. content

\begin{tabular}{|c|c|c|c|}
\hline \multicolumn{4}{|c|}{$\begin{array}{c}\text { TABLE-1 } \\
\text { PHYSICAL PROPERTIES OF THE DICLOFENAC SODIUM GRANULES/POWDERS } \\
\text { PREPARED BY USING PVP HYDROGELS AS A SUSTAINING AGENT }\end{array}$} \\
\hline \multirow{2}{*}{ Properties } & \multicolumn{3}{|c|}{ Formulations } \\
\hline & $2 \mathbf{a}$ & $2 \mathbf{b}$ & $2 c$ \\
\hline Angle of repose & $29.33 \pm 0.04$ & $30.37 \pm 0.07$ & $27.38 \pm 0.09$ \\
\hline Looses bulk density (LBD) (g/mL) & $0.45 \pm 0.05$ & $0.46 \pm 0.04$ & $0.48 \pm 0.02$ \\
\hline Compressibility index (\%) & $12.56 \pm 0.05$ & $14.35 \pm 0.05$ & $16.54 \pm 0.05$ \\
\hline Drug content of granules (\%) & $99.73 \pm 0.05$ & $98.55 \pm 0.03$ & $98.98 \pm 0.02$ \\
\hline
\end{tabular}


uniformity test and active ingredient. The results of tests were $99.85 \pm 0.07,99.66 \pm 0.07$ and $98.88 \pm 0.06 \%$, respectively.

Hardness of the tablet is an important physical parameter to be taken into account in the manufacturing of a controlled release dosage form. The results of friability were in the official limits i.e. less than $1 \%$. It showed that the manufactured tablets have sufficient resistance to any potential abrasion, shock and friction during handling, transport or storage. Statistically friability for the formulations $\mathbf{2} \mathbf{a}$ and $\mathbf{2} \mathbf{b}$ were not significant $\mathrm{P}$ was greater than 0.05 , while formulation $\mathbf{2 c}$; it was highly significant $\mathrm{P}$ was more than 0.005 . The thickness and weight variation of the tablets for all formulations were in the acceptable range and statistically were observed highly significant $\mathrm{P}$ was less than 0.005 in both cases. The drug content of the tablets was in the range of $98.84 \pm 0.05$ to $99.54 \pm 0.02 \%$ which was also in the official limit of the pharmacopoeia this revealed the uniform distribution of drug in granules ${ }^{20}$.

Drug releases from compressed tablets containing diclofenac sodium and poly( $N$-vinyl-2-pyrrolodine) hydrogel: The matrix tablets of diclofenac sodium were manufactured with poly( $N$-vinyl-2-pyrrolodine) hydrogel by the use of $1: 1$, $1: 2$ and 1:3 ratios. The matrix tablets were subjected to weight variation tests as per United Stated Pharmacopoeia (USP) standards. The matrix tablets of dissolution testing were carrying out according to dissolution apparatus-II and the results are shown in Table-2. The hardness ranged from 6.5-8.3 Kg with $\mathrm{S} . \mathrm{D}=0.07432$ and $\mathrm{RSD}=0.18 \%$ and thickness ranged from $5.5-8 \mathrm{~mm}$ with $\mathrm{S} . \mathrm{D}=0.11005$ and $\mathrm{RSD}=0.25 \%$ and weight variations tests was 400-800 mg with $\mathrm{S} . \mathrm{D}=2.55432$ and RSD $=2.24 \%$. Different kinetic models were used to analyze the release mechanism of drug from compressed tablet with hydrogel ${ }^{21}$.

Release of diclofenac sodium from 2a formulation: The release of drug was fast and about $50 \%$ diclofenac sodium was released in $3 \mathrm{~h}$ and $84 \%$ of drug was released in $6 \mathrm{~h}$. The release of drug was monitored for $6 \mathrm{~h}$ and followed the Hixon Crowell kinetics model as shown in Table-2. The drug polymer ratio 1: 1 failed to sustain the drugs release, as the entire drug released in $6 \mathrm{~h}$. The cumulative amount of diclofenac sodium was released from matrix tablets at different intervals of time and was fitted to zero-order kinetics using the test square method for evaluating the release of drug parameters ${ }^{22}$. The data were also fitted to Hixon-Crowell, Higuchi equation and Korsmeyer's model for finding out the release of drug mechanism from the formulations. The percentage of released drug from the matrix tablets were plotted $v s$. time on a log-log scale and examined for linearity by means of least squares method. The correlation coefficient was calculated and used to find the fitness of the data ${ }^{23}$. The drug release rate from the matrix tablets increased with a decrease in polymer proportion due to decrease in strength of the gel as well as formation of a gel layer with a large diffusion path ${ }^{24}$. The data was subjected to various release kinetic models to understand the diclofenac sodium release form the poly( $N$-vinyl-2-pyrrolodine) hydrogel. The release mechanism of drug from these formulations was evaluated by fitting the data into first-order ${ }^{25}$, Higuchi' ${ }^{26}$, zero order $^{27}$, Hixon Crowell ${ }^{28}$ and Korsmeyer's model ${ }^{29}$.

It was found that the in vitro diclofenac sodium release from the $\mathbf{2 a}$ best fits to the Hixon-Crowell as the $\mathrm{R}^{2}$ value obtained was the highest $(0.9816)$ indicating polymer erosion and dissolution. The good linearity $\left(\mathrm{R}^{2}=0.9416\right)$ was obtained for Higuchi model indicating the drug release followed Fickian diffusion. The "n" value of the Korsmeyer's model was 1.22668 as shown in Table-2 that indicated the super case-II diffusion ${ }^{24}$.

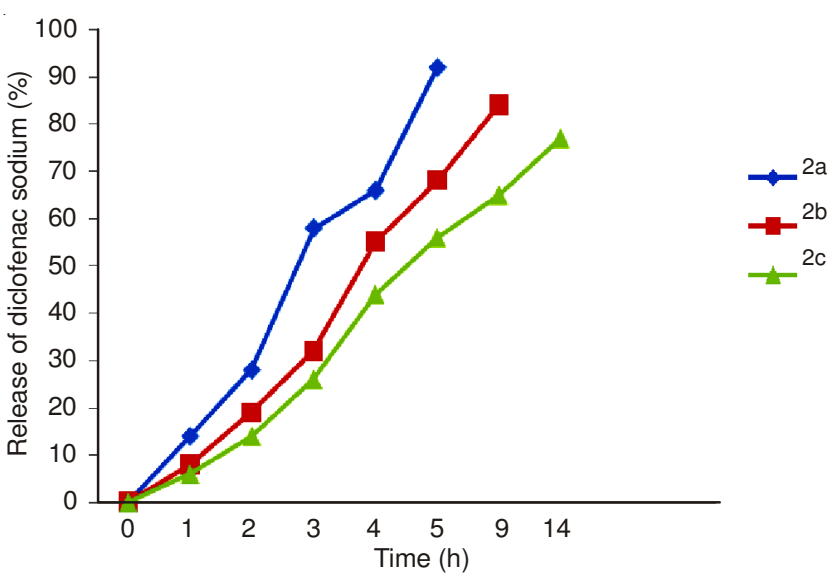

Fig. 1. Graphical representation of release of diclofenac sodium from tablets containing diclofenac sodium and poly( $N$-vinyl-2pyrrolodone) hydrogel.

Release of diclofenac sodium from $2 \mathrm{~b}$ formulation: The diclofenac sodium tablets compressed with polymer in the ratio of 1:2 prolong the drug release for 9 h i.e. $84 \%$ of the drug was released as shown in Fig. 1. However, the release was not sufficient for maintaining the action of drug but it showed better drug retardation as compared with 1: 1 drug polymer ratio. The hardness was $7.5 \mathrm{Kg}$ with S.D = 0.18635 and with $\mathrm{RSD}=$ $0.18 \%$ and thickness was $8 \mathrm{~mm}$ with S.D $=0.23002$ and with $\mathrm{RSD}=0.23 \%$. The tablets were good and weight variation test was $600 \mathrm{mg}$ with S.D $=2.18789$ and with $\mathrm{RSD}=2.56 \%$. Different kinetic model were used to analyze the release mechanism of drug from compressed tablet with hydrogel.

TABLE-2

in vitro RELEASE KINETICS OF DICLOFENAC SODIUM FROM 2a, 2b AND 2c FORMULATIONS

\begin{tabular}{|c|c|c|c|c|c|c|c|c|}
\hline $\begin{array}{l}\text { Drug polymer } \\
\text { ratio } \\
\end{array}$ & $\begin{array}{l}\text { Drug release } \\
\text { time }(\mathrm{h})\end{array}$ & $\begin{array}{l}\text { Zero } \\
\text { Order }\end{array}$ & $\begin{array}{l}\text { First } \\
\text { order }\end{array}$ & $\begin{array}{l}\text { Higuchi } \\
\text { model }\end{array}$ & $\begin{array}{c}\text { Hixon } \\
\text { Crowell }\end{array}$ & \multicolumn{3}{|c|}{ Korsmeyer's } \\
\hline & Diclofenac sodium & $\mathrm{R}^{2}$ & $\mathrm{R}^{2}$ & $\mathrm{R}^{2}$ & $\mathrm{R}^{2}$ & $\mathrm{R}^{2}$ & $\mathrm{~N}$ & $\mathrm{~K}$ \\
\hline $1: 1$ & $0-6$ & 0.9025 & 0.8089 & 0.9714 & 0.9366 & 0.9655 & 1.2668 & 1.0423 \\
\hline \multirow{3}{*}{$1: 2$} & $0-9$ & 0.9736 & 0.8863 & 0.9564 & 0.9862 & 0.9798 & 1.0185 & 1.0373 \\
\hline & $0-5$ & 0.9469 & 0.8889 & 0.9766 & 0.9293 & 0.9519 & 1.2435 & 1.0351 \\
\hline & $5-9$ & 0.9414 & 0.8991 & 0.9697 & 0.9391 & 0.9888 & 1.4367 & 1.0351 \\
\hline \multirow{3}{*}{$1: 3$} & $0-6$ & 0.9191 & 0.8439 & 0.9554 & 0.9698 & 0.9455 & 1.0733 & 0.9538 \\
\hline & $6-14$ & 0.9278 & 0.8962 & 0.9875 & 0.9292 & 0.9898 & 1.4793 & 1.0351 \\
\hline & $0-14$ & 0.9494 & 0.893 & 0.9374 & 0.9678 & 0.9797 & 1.1773 & 1.0949 \\
\hline
\end{tabular}


in vitro Dissolution drug release data obtained for the formulation $\mathbf{2 b}$ was fitted to different mathematical models to explore the drug kinetics and release mechanism. The highest value for $\mathrm{R}^{2}$ was obtained for Hixson-Crowell (0.9862) followed by 0 order (0.9736) Fig. 1. The value (1.0185) of release exponent "n" obtained with Korsmeyer's-Pappas equation suggests that drug release from $\mathbf{2 b}$ formulation followed anomalous transport super case II diffusion ${ }^{30}$.

Release of diclofenac sodium from $2 \mathrm{~b}$ formulation (from 0-5 h): in vitro Dissolution data obtained for the formulation $\mathbf{2 b}$ from 0-5 h was fitted to different mathematical models to explore the drug kinetics and release mechanism. The values showed best linearity for the Higuchi model $\left(R^{2}=0.9766\right)$. The highest value for $\mathrm{R}^{2}$ was obtained for Higuchi model $\left(R^{2}=0.9766\right)$ followed by 0 order $(0.9469)$. The value of $n$ (Korsmeyer's model) was 1.2435 indicates super case II type of release. As the value of $\mathrm{n}=0.45$ indicating Fickian (case 1 ) release $>0.45$ but $<0.89$ for non-Fickian (anomalous) release and $>0.89$ indicates super case II type of release. Generally release of the diclofenac sodium from the hydrogel followed both diffusion and erosion.

Release of diclofenac sodium from $2 b$ formulation (from 5-9 h): Release rate of diclofenac sodium from 5-9 $\mathrm{h}$ it was established that the in vitro dissolussion testing of diclofenac sodium release from the $\mathbf{2} \mathbf{b}$ formulation of matrix tablets showed best fits to the Higuchi model as the $\mathrm{R}^{2}$ value obtained was the highest (0.9697) indicating that the drug release rate followed Fickian diffusion. The good linearity $\left(\mathrm{R}^{2}\right.$ $=0.9414$ ) for 0 order indicated that the rate of drug release is independent of concentration of drug. The value of " $n$ " (Korsmeyer's model) was 1.4367 indicated super case II type of release. Normally, rate of diclofenac sodium release from the matrix tablets followed both process of diffusion and erosion. From the above results, it was clear that the release of diclofenac sodium from matrix tablets followed both mechanisms of release i.e. diffusion and erosion weather the release rate of drug from matrix tablets was from 0-5 or the release rate of drug was from 5-9 h.

Release of diclofenac sodium from $2 \mathrm{c}$ formulation: The released of drug from compressed tablets with drug and hydrogel in 1:3 ratios was studied and $72 \%$ of diclofenac sodium was released in $14 \mathrm{~h}$. While within $6.5 \mathrm{~h}$ about $60 \%$ of the diclofenac sodium was released from matrix tablets as shown in Fig. 1. Matrix tablets were prepared in this ratio of drug and hydrogel was adequate for sustaining the release of the diclofenac sodium. The hardness was $8.1 \mathrm{Kg}$ with $\mathrm{S} . \mathrm{D}=$ 0.09876 and with RSD $=0.18 \%$ and thickness was $7.8 \mathrm{~mm}$ with S.D $=0.33006$ and with $\mathrm{RSD}=0.24 \%$. The tablets were good and weight variation test was $800 \mathrm{mg}$ with S.D $=2.18789$ and with $\mathrm{RSD}=2.26 \%$. Different kinetic model were used to analyze the release mechanism of drug from compressed tablet with hydrogel.

in vitro Dissolution drug release obtained for the formulation $\mathbf{2 c}$ was fitted to different mathematical models to explore the drug kinetics and release mechanism. The values showed best linearity for the Hixon Crowell model $\left(\mathrm{R}^{2}=\right.$ 0.9878). Values for regression coefficient for the various equations are summarized in Table-2. The highest value for $\mathrm{R}^{2}$ was obtained for Hixon Crowell model (0.9878). The release data also showed reasonable linearity for zero order $\left(R^{2}=0.9692\right)$ which indicate that the release of drug is independent of the concentration of drug within the gel. The"n" value (1.1773) of release exponent obtained with Korsmeyer's-Pappas equation suggests that release of drug from $2 \mathbf{c}$ formulation followed anomalous transport super case II.

The rate of drugs release was decreased with decreasing the drugs solubility. Because the drug which is dissolved by water first at the surface and then through pores penetrate into the matrix due to which hydrogel gelling produced ${ }^{31}$. Released of the drugs which are dissolved in water, through diffusion from hydrogel and finally as the water reaches the centre of hydrogel, release rate of drug reduce because of reduction in the concentration of dissolved drugs to less than its solubility. The drugs release from hydrogel also slow down due to low drugs solubility and the slow erosion of the matrix ${ }^{24}$. As any decrease occurred in drug solubility, variation in n" value was observed from anomalous release to near zero-order release rate. More than one process was involved in the released of drugs from matrix which is due to relative complexity of these tablets $^{32}$.

Release of diclofenac sodium from $2 \mathrm{c}$ formulation (from 0-6 h): Furthermore, the releases of drug from 0-6 h, it was observed that the in vitro release of diclofenac sodium from the $\mathbf{2 c}$ best fits to the Hixon-Crowell (Fig. 1) as the $\mathrm{R}^{2}$ value obtained was the highest (0.9698) indicating the release of drug was by erossion. Fig. 3 indicates that good linearity $\left(\mathrm{R}^{2}=0.9554\right)$ was obtained for Higuchi indicating the release of drug followed Fickian diffusion. The value of $n$ of Korsmeyer's model indicates that the drug release is followed by mixed mechanism i.e. erosion and diffusion. The releases of drug from 6-14 $\mathrm{h}$ followed the Higuchi equations $\left(\mathrm{R}^{2}=\right.$ 0.9875 ) followed by the Hixon-Crowell model and Zero-order as shown in Table- 2 and the value of diffusion exponent was 1.0733 indicating that the release of diclofenac sodium from matrix tablets showed super case-II diffusion ${ }^{24}$.

Release of diclofenac sodium from $2 \mathrm{c}$ formulation (above 6 h): Furthermore, the drug releases data above $6 \mathrm{~h}$ it was observed that the in vitro dissolussion testing of diclofenac sodium release from the $2 \mathrm{c}$ formulation of matrix tablets showed best linearity with Hixon-Crowell as the $\mathrm{R}^{2}$ value obtained was the highest $(0.9698)$ indicating the release of drug was by erossion. indicates that good linearity $\left(\mathrm{R}^{2}=\right.$ 0.9554) was obtained for Higuchi indicating the release of drug followed Fickian diffusion. The "n" value of diffusion exponent was 1.0733 indicating that release of diclofenac sodium followed the super case-II diffusion ${ }^{24}$.

\section{Conclusion}

The major intention of the study was to synthesize and developed sustained release tablets of anti asthmatic drugs and for this reason one drugs was selected that is diclofenac sodium. The conversion of monomers to PVP hydrogels in the present methods was very high. The diclofenac sodium formulations (2a, 2b and 2c) containing PVP hydrogels as sustaining materials were proved to be the suitable candidates for retarding the drug release up to $14 \mathrm{~h}$ at drug to polymer ratio of $1: 3$. While the formulations containing diclofenac sodium and PVP in 1:1 and 1:2 were able to sustain the release only up to 
7 and $9 \mathrm{~h}$, respectively at this ratio. The present study showed that poly(vinyl pyrrolidone) hydrogels can be a good agent that can be used for controlled release of the drug. In conclusion matrix tablets formulations with drug to poly(vinyl pyrrolidone) ratio 1:3 sustained the release of drugs and also showed good in vitro release for diclofenac sodium for $14 \mathrm{~h}$ and can be use clinically as once a day dose.

\section{ACKNOWLEDGEMENTS}

The authors are thankful to the Deanship of Scientific Research, King Saud University, Riyadh, for funding the work through the research group Project no. RGP-210.

\section{REFERENCES}

1. S. Zuleger and B.C. Lippold, Int. J. Pharm., 217, 139 (2001).

2. M. Rahmatullah, H.V. Gangadharappa and R. Neelkant, Pak. J. Pharm. Sci., 21, 350 (2008).

3. J. Berger, M. Reist, J.M. Mayer, O. Felt and R. Gurny, Eur. J. Pharm. Biopharm., 57, 35 (2004).

4. G. Aggarwal and A. Sharma, Int. J. Pharma. Bio. Sci., 1 (2010).

5. K.-S. Chen, Y.-A. Ku, C.-H. Lee, H.-R. Lin, F.-H. Lin and T.-M. Chen, Mater. Sci. Eng., 25, 472 (2005).

6. E. Ayano, K. Nambu, C. Sakamoto, H. Kanazawa, A. Kikuchi and T. Okano, J. Chromatogr. A, 1119, 58 (2006).

7. W.F. Rayburn, B.L. Powers, T.F. Plasse, D. Carr and M. Di Spirito, J. Soc. Gynecol. Investig., 13, 112 (2006).

8. M.A. Azrin, J.F. Mitchel, D.B. Fram, C.A. Pedersen, R.W. Cartun, J.J. Barry, L.M. Bow, D.D. Waters and R.G. McKay, Circulation, 90, 433 (1994).

9. A.L. Brown, E.M. Srokowski, X.Z. Shu, G.D. Prestwich and K.A. Woodhouse, Macromol. Biosci., 6, 648 (2006).

10. N. Flores-Ramirez, E.A. Elizalde-Peña, S.R. Vásquez-Garcia, J. González-Hernández, A. Martinez-Ruvalcaba, I.C. Sanchez, G. LunaBárcenas and R.B. Gupta, J. Biomater. Sci. Polym. Ed., 16, 473 (2005).
11. K.A. Mehta, M. Serpil Kislalioglu, W. Phuapradit, A. Waseem Malick and N.H. Shah, Drug Dev. Ind. Pharm., 28, 275 (2002).

12. F.J. Holly and M.F. Refojo, in ed.: J.D. Andrade, Water Wettability of Hydrogels; In: Hydrogels for Medical and Related Applications, Washington, DC: Am. Chem. Soc, pp. 252-266 (1976).

13. U.V. Banakar, Dissolution and Bioavailability; In: Pharmaceutical Dissolution Testing Marcel Dekker INC, New York, pp. 347-384 (1992).

14. M.V. Risbud, A.A. Hardikar, S.V. Bhat and R.R. Bhonde, J. Control. Rel., 68, 23 (2000).

15. E. Karadag, O.B. Uzum and D. Saraydin, Eur. Polym. J., 38, 2133 (2002).

16. L. Chen, Z. Tian and Y. Du, Biomaterials, 25, 3725 (2004).

17. V. Dash, S.K. Mishra, M. Singh, A.K. Goyal and G. Rath, Sci. Pharm., 78, 93 (2010)

18. J. Mark, K. Ngai, W. Graessley, L. Mandlekern, E. Samulski, J. Koenig and G. Wignall, Physical Properties of Polymers, Cambridge: University Press, edn 3 (2004).

19. A.M. Atta and K.F. Arndt, Polym. Int., 53, 1870 (2004).

20. H. Kaplan and A. Guner, J. Appl. Polym. Sci., 78, 994 (2000).

21. N. Sanabria-Delong, A.J. Crosby and G.N. Tew, Biomacromolecules, 9, 2784 (2008).

22. D. Zugic, P. Spasojevic, Z. Petrovic and J. Djonlagic, J. Appl. Polym. Sci., 113, 1593 (2009).

23. W. Xue, M.B. Huglin and T.G.J. Jones, Eur. Polym. J., 41, 239 (2005).

24. T.R. Hoare and D.S. Kohane, Polymer, 49, 1993 (2008).

25. S.W. Kim, Y.H. Bae and T. Okano, Pharm. Res., 9, 283 (1992).

26. J. Kopecek and J. Yang, Polym. Int., 56, 1078 (2007).

27. C.C. Lin and A.T. Metters, Adv. Drug Deliv. Rev., 58, 1379 (2006).

28. N.A. Peppas, P. Bures, W. Leobandung and H. Ichikawa, Eur. J. Pharm. Biopharm., 50, 27 (2000).

29. H.G. Shivakumar, C.S. Satish and K.P. Satish, Indian J. Pharm. Sci., 68, 133 (2006).

30. N. Shah, G. Zhang, V. Apelian, F. Zeng, M.H. Infeld and A.W. Malick, Pharm. Res., 10, 1693 (1993).

31. G. Xu and H. Sunada, Chem. Pharm. Bull. (Tokyo), 43, 483 (1995).

32. T.D. Reynolds, S.H. Gehrke, A.S. Hussain and S.L. Shenouda, J. Pharm. Sci., 87, 1115 (1998) 